Maria Celi Chaves Vasconcelos

Universidade do Estado do Rio de Janeiro, Rio de Janeiro, RJ, Brasil

Paulo Marcelo Rezzutti

Instituto Histórico e Geográfico de São Paulo, São Paulo, SP, Brasil

\title{
A Marquesa de Santos e o gosto pelo poder: de "favorita" à militante liberal
}

Resumo: Neste artigo são enfocados aspectos da biografia de Domitila de Castro Canto e Melo, especialmente sua relação com o poder, desenvolvida desde a condição de amante do imperador Pedro I, registrada nas cartas trocadas entre os missivistas no período de 1822 a 1829 , até sua longeva vida após a saída da Corte. Os procedimentos metodológicos remetem a uma pesquisa bibliográfica, dialogando particularmente com autores que se debruçaram sobre a recomposição da vida da marquesa e outros que analisaram a situação das mulheres e suas possibilidades no oitocentos. Conclui-se que a marquesa de Santos, diferentemente da maioria das mulheres da sua época e contexto, possuía uma predileção pela política, influenciando o imperador enquanto ocupava o lugar de "favorita", bem como continuando envolvida em assuntos políticos e partidários já em sua residência definitiva na Província de São Paulo.

Palavras-chave: Marquesa de Santos, Imperador Pedro I, condição feminina, relações de poder

\section{As favoritas reais e o poder feminino nas Cortes: 0 caso Domitila}

As amantes reais sempre exerceram certo fascínio sobre a imaginação não só de seus contemporâneos, mas das gerações posteriores, que lhes atribuíam qualidades e poderes, alimentando a curiosidade sobre essas mulheres que, em um mundo dominado por homens, possuíam o direito de se sobressair, sem que pertencessem à nobreza ou

\section{(c) ()}

Esta obra está sob licença Creative Commons. 
tivessem realizado qualquer ação meritória para tal. Sua única condição diferenciada é terem sido amadas ou desejadas por homens poderosos, chefes de governo e de estado, sobre os quais exerciam marcada influência.

Para Elizabeth $A B B O T T$ (2016, p. 21), a instituição da condição de amante é indissociada do casamento, pois eram os casamentos arranjados que produziam nos cônjuges a ideia de que tinham como único propósito garantir alianças, negócios, dar continuidade a uma linhagem, sem que necessariamente houvesse espaço para o "amor romântico". Nesse contexto, muitas sociedades "permitiam aos homens que não se dispusessem a reprimir e sublimar seus impulsos românticos e libidinosos", que estes fossem satisfeitos fora do casamento com concubinas, gerando, por vezes, situações em que a amante era infinitamente mais influente do que a própria esposa.

Ana Cristina PEREIRA e Joana TRONI (2009) localizam na França o modelo que teria contribuído para moldar o padrão de comportamento das amantes reais das casas monárquicas ocidentais, particularmente, a partir da dinastia dos Valois,' quando as denominadas "favoritas" adquirem notoriedade na Corte, passando a rivalizar com a rainha oficial tanto o protagonismo nos diferentes ambientes, como a influência e atuação ${ }^{2}$ sobre o rei e os assuntos de estado. Contudo, a abrangência do poder concedido a cada uma delas, estava, também, relacionada aos traços de personalidade, considerando a imensa quantidade de mulheres de diferentes extratos sociais que, por algum tempo, ocuparam o posto de favoritas dos reis. De acordo com as autoras Pereira e Troni (2009), certo é que todas elas "desempenharam papéis políticos cruciais" ( $p .10)$, chegando até a ter uma função de espionagem junto ao soberano com quem compartilhavam a alcova.

Grosso modo, compartilihar o quarto do rei já era um privilégio para poucos, como descreve Michelle PERROT (2011) na sua História dos quartos, pois esse era "o verdadeiro escritório do rei, seu local de trabalho" (p. 37). Nele eram recebidas as autoridades, bem como se realizava grande parte das audiências privadas. Entrar sem avisar ou sem ter marcado hora era uma distinção absoluta, reservada a parentes muito próximos, além do que, "passar pelos fundos", como cita Perrot (201 1, p. 37), ou seja, entrar por portas veladas ou facultadas somente para algumas pessoas, "era um favor supremo", concedido aos íntimos, entre eles, as favoritas. Assim, entre os súditos que gozavam de amplos privilégios estavam incluídas as amantes reais que, como assinala Perrot (2011), também "desfrutavam de apartamentos espaçosos, no corpo central do castelo, perto do rei, que exibia sem complexo sua bigamia e mesmo sua poligamia" (p. 38). Essas extensas prerrogativas, que iam do lugar exclusivo reservado aos seus aposentos particulares até a licença para falar ou escrever bilhetes ao soberano a qualquer momento, já demonstram que a favorita, não só na Corte francesa, mas junto a muitas outras casas reais, era considerada um assunto da "privance"3 do rei.

Nesse padrão de intimidade, não há dúvida de que o grau de influência e ałuação dessas mulheres, muitas vezes, extrapolava os gostos, caprichos, simpatias e antipatias e se tornava bem mais perigoso, especialmente, quando se tratavam de mulheres mais

\footnotetext{
' A Casa de Valois é o ramo da dinastia capetiana que reinou na França entre 1328 e 1589. Sucedeu aos Capetíngios diretos e precedeu os capetíngios Bourbons. Seu nome deriva do apanágio dado a Carlos de Valois (1270-1325), filho de Filipe III, o ousado, e pai do rei Filipe VI. Disponível em: https://pt.scribd.com/ document/249174297/Casa-de-Valois.

${ }^{2}$ De acordo com André de LemOs FREIXO e Patrícia COELHO (2015), a palavra "influência" traz consigo uma carga semântica que pode transmitir uma ideia equivocada de recepção passiva dos comportamentos e discursos alheios, por isso se optou por reunir os termos influência e atuação.

${ }^{3}$ De acordo com Perrot $(2011$, p. 39), "privance" significa familiaridade. Segundo a autora, esse termo desapareceu depois do século XVII.
} 
inteligentes e determinadas a influir nos destinos do país, ou pelo menos na vida dos que estavam nas posições de comando no reino. Perrot (2011 , p. 34) cita como exemplo madame de Maintenon, última mulher de Luís XIV, com quem, após a morte da rainha, o rei acabou se casando em uma cerimônia noturna e quase secreta. A ela é atribuída "uma influência considerável, exercida com descrição. Ela escutava sem intervir, mas encontrava os ministros antes das entrevistas com o rei, sempre atenta à atribuição dos empregos e favores" (PERROT, 2011 , p. 40).

Além dos ouvidos sempre atentos às decisões do rei, as favoritas também tinham que se esforçar para serem mantidas nessa função, o que exigia destreza suficiente para superar os oponentes e as demais aspirantes a esse cargo, pois, conforme descreve Eduard FUCHS (1996), "o amor no Antigo Regime ${ }^{4}$ era um mero passatempo, um entretenimento, um jogo praticado, segundo as circunstâncias, com dezenas de outras pessoas e em que, em qualquer caso, se pode mudar constantemente de par"5 (p. 46). De toda forma, não há dúvida de que a ascensão de uma mulher à condição de favorita real era movida pelos favores sexuais, ou outros, também relacionados a estes, tornando a estabilidade no "cargo" bastante tênue - à medida que o tempo passava, o encanto se desvanecia, ou mesmo, uma nova paixão ocupava o lugar da anterior. Assim, aproveitar ao máximo o lugar principal na cama e na audiência do rei era o que faziam as mais lúcidas, arregimentando aliados entre os beneficiários dos favores reais e livrando-se dos inimigos, seja no momento vivido, mas também para os dias em que não mais pudessem gozar do prestígio real.

As sucessoras de madame de Maintenon na França e no resto do ocidente, em que pese o surto puritano 6 ainda muito presente no século XVIII, já não prezavam mais pela discrição, mas, ao contrário, exibiam sua condição de amantes reais e de detentoras de tudo o que se poderia extrair dela, seja concretamente, ou apenas no plano do imaginário popular. Para Thomson (2010), o palácio de Versalhes simbolizava esse mundo, com suas ligações perigosas, "o culto efêmero da beleza e dos objets d'art" (p. 255), das danças complexas e do estilo rococó.

D. Pedro I, imperador brasileiro, nas primeiras décadas do século XIX, após muitos casos extraconjugais, toma-se de paixão por uma mulher, reeditando o modelo das favoritas reais, em todos os seus aspectos, incluindo-se a influência e atuação política. Todavia, faltou ao imperador a percepção de que o Antigo Regime havia perecido, particularmente, com a contribuição das favoritas reais, simbolizadas pela marquesa de Pompadour e de sua sucessora nos favores a Luís XV, a nada nobre madame Du Barry (PEREIRA \& TRONI, 2009).

É nesse cenário, quando grassavam mudanças nas monarquias europeias mais atentas ao sinal das transformações que se avizinhavam na era pós-napoleônica, que desponta nos trópicos uma mulher que seria comparada às grandes amantes reais, cujo poder era, de acordo com a imaginação pública, ilimitado, fazendo do soberano apenas um fantoche de seus caprichos.

A escolhida pelo destino para esse lugar na história brasileira foi batizada como Domitila de Castro Canto e Melo, uma mulher nascida no século XVIII, que viveu um romance com o monarca, por sete anos, do qual sobreviveram duas filhas reconhecidas pelo soberano. Na condição de favorita do imperador Pedro I, foi nomeada dama camarista da imperatriz em 4 de abril de 1825, viscondessa de Santos em 12 de outubro de 1825 e, um

\footnotetext{
${ }^{4}$ Ancien Régime no original.

${ }^{5}$ Texto original em Espanhol. Tradução livre dos autores.

${ }^{6}$ De acordo com Oliver THOMSON (2010, p. 239), o Puritanismo era uma forma inglesa do Calvinismo que começou a emergir no reinado de Elizabeth I (1558-1603).
} 
ano depois, marquesa de Santos, títulos dados a ela, segundo Paulo REZZUTTI (2012a), não pelos "bons serviços prestados à imperatriz", mas como escreve o próprio imperador: "querendo dar um público testemunho do alto apreço em que tenho os serviços prestados pela Viscondessa de Santos, Dona Domitila de Castro Canto e Melo. [...] Hei por bem acrescentá-la em grandeza com o Título de Marquesa de Santos" (p. 120).

A favorita do imperador brasileiro não somente superava em títulos nobiliárquicos suas pares europeias, como a distribuição de títulos não se limitava apenas à cortesã, mas era estendida à família:

O pai de Titília ${ }^{7}$ foi feito visconde de Castro, o cunhado Boaventura recebeu o título de barão de Sorocaba, todos os irmãos foram feitos gentis-homens do paço, um deles recebeu a patente de coronel, e dois primos passaram ao cargo de guarda-roupas do imperador (REZZUTTI, 2012a, p. 121).

O presente estudo trata, portanto, de aspectos biográficos da marquesa de Santos que demonstram suas relações com o poder e a sua permanente predileção pela política, cultivadas desde a sua influência/atuação sobre o imperador Pedro I, registrada nas cartas trocadas entre os amantes, assim como em outros escritos, anos após a sua saída da Corte Imperial, já como ilustre moradora da Província de São Paulo. As cartas tomadas como fontes inserem-se no conjunto das chamadas "escritas ordinárias", caracterizadas por Maria Teresa Santos CUNHA (2011, p. 252) como aquelas que proporcionam aos historiadores muitas das maneiras de rastrear os modos de viver e de pensar de determinada época, fazendo com que a leitura desses registros pessoais permita revisitar parte da história de seus autores, cuja existência possui constatada similaridade com a de outros que apresentavam condição social semelhante e as mesmas expectativas em relação à realidade, que, nas palavras de Balandier, as "ultrapassa" e "modela" (apud Franco FERRAROTII, 1983, p. 8). Para Ferrarotti (1983, apud Maria Celi Chaves VASCONCELOS, 2014), trata-se de "uma antropologia que considera cada homem como a síntese individualizada e ativa de uma sociedade" (p. 51).

Nesse sentido, entendendo que a história individual é única, "mas essa história individualiza a história social coletiva de um grupo ou de uma classe" (Françoise DIGNEFFE, 1997, p. 207), significando, ao mesmo tempo, produto e expressão dessa classe, os registros da vida da marquesa podem levar ao entendimento das estratégias de influência e atuação das amantes reais sobre o soberano e, consequentemente, suas relações com o poder.

Assim, o objetivo do artigo é apresentar fragmentos de fontes, especialmente egodocumentos, que demonstram o gosto e a influência/atuação da marquesa na vida política brasileira, iniciada em sua convivência com o imperador e perpetuada ao logo de toda a sua existência, embora não contasse mais com os favores daquele. Em um plano mais específico, buscou-se, a partir da leitura das cartas publicadas, inferir sobre a intervenção e o posicionamento político da marquesa, tanto na Corte, enquanto permaneceu nela, como após, ao se retirar para São Paulo, na participação nos movimentos e na condução dos destinos daquela região.

Para a escrita do texto, os procedimentos metodológicos basearam-se em uma pesquisa bibliográfica em autores que trabalharam com tema semelhante, entre eles, Elizabeth Abbott (2016), Michelle Perrot (1998; 2005; 2008; 2011), Oliver Thomson (2010), Pereira e Troni (2009) e Eduard Fuchs (1996). Igualmente, foram consultados autores que demonstram a importância dos egodocumentos, sobretudo escritas íntimas, na reconstrução de um escopo biográfico, como Maria Teresa Cunha (2011), Franco Ferrarotti (1983) e

${ }^{7}$ Nome com o qual a marquesa era chamada nas cartas pelo imperador Pedro I. 
Françoise Digneffe (1997). No que alude à marquesa, o referencial reportou-se, de maneira especial, às publicações de Paulo Rezzutti (201 1; 2012a; 2012b) e Alberto RANGEL (1928; 1984).

A escolha dos biógrafos Rezzutti e Rangel como referenciais básicos ao estudo ocorreu por terem sido esses autores os que trabalharam arquivos inéditos de cartas trocadas entre os amantes Pedro e Domitila. Rezzutti, em 2010, localizou o paradeiro e pesquisou a coleção de 94 cartas constantes do acervo da Hispanic Society of America. ${ }^{8}$ Alberto Rangel, diplomata brasileiro, contemporâneo da princesa Isabel e do conde D'eu, em visita ao castelo da família exilada na França, teve contato com o acervo histórico da família imperial brasileira, então guardado no Castelo D'eu que, hoje, transferido para o Brasil, se divide entre o Arquivo Histórico da Família Imperial e o Arquivo Grão Pará. Alberto Rangel, nos anos de 1920, foi a primeira pessoa a fazer um catálogo dos documentos pertencentes a esses arquivos, encontrando reminiscências do romance entre d. Pedro l e a marquesa de Santos, sobre o qual fez dois livros.

Tomando como fontes as obras citadas, o estudo em pauta pretende recompor uma pequena parte da história vivida pelos personagens, em meio à contradição do amor, admiração, e do ódio e repugnância causadas pela exacerbação do romance feita pelos dois amantes, quando d. Pedro nomeia a marquesa dama camarista da imperatriz Leopoldina, fazendo com que a favorita passasse a ser assunto, até mesmo, dos relatórios produzidos pelos diplomatas estrangeiros no Brasil. Pode-se afirmar que essa nomeação iniciou a trajetória pública de Domitila como favorita do imperador, a ponto de merecer menções e investigações por parte dos agentes estrangeiros na Corte, que buscavam saber mais sobre quem era essa mulher que ocupava um cargo público com acesso à ala íntima dos soberanos. Nesse momento, a futura marquesa passa de simples amante a uma condição de poder que merece atenção no jogo diplomático internacional, bem como no jogo político nacional, no qual já vinha se insinuando desde a sua chegada ao Rio de Janeiro.

Articulando as cartas recebidas e a escrita pela marquesa, o artigo tem como fio condutor de seu enredo a participação política de Domitila de Castro registrada em diferentes fontes, inicialmente, quando de sua ida para o Rio de Janeiro; em um segundo momento, durante os anos que antecederam a tentativa do imperador de "exilar" a amante em São Paulo, e, finalizando, após sua partida definitiva da Corte, que resultou ainda em muitos anos vividos na cidade de São Paulo.

Ao final, o estudo demonstra que a marquesa de Santos é um exemplo do poder emanado dos favores sexuais ao soberano, que lhe atribui não apenas riqueza, poder e distinção social, mas também um imenso gosto pela política que a acompanhará por toda a vida.

\footnotetext{
${ }^{8}$ De acordo com Rezzutti $(2011$, p. 21), essa coleção é bastante singular e chama atenção a forma como foi anunciada por um antiquário alemão, antes de seu atual paradeiro na Hispanic Society of America: "Pedro I, (1822-1831), cartas de amor de Dom Pedro I, Imperador do Brasil, à Marquesa de Santos. 1827-28. Coleção altamente interessante de 94 cartas de amor não impressas, escritas de forma cursiva à mão pelo primeiro imperador do Brasil (1822-1831) em língua portuguesa. Abrange 116 páginas de texto in $4^{\circ} \mathrm{e} 8^{\circ}$. Algumas mostram ainda o endereço da destinatária e o selo imperial. $O$ vocativo é normalmente querida marquesa filha, meu bem, meu beminho (sic), minha boa senhora, meu amor, meu coração, minha fililia (sic). E como assinatura encontra-se Pedro, o imperador, e na maior parte das vezes $O$ Demonão, um apelido que o imperador usava entre seus amigos. As respostas da marquesa não estão disponíveis. As cartas são uma excepcional contribuição para a caracterização do imperador e o conhecimento de sua vida íntima amorosa assim como de personalidades e hábitos da corte. Elas mostram como ele se deixou dominar por sua paixão, o que no final o levou a tal antagonismo com seu povo que uma insatisfação geral rompeu e ele teve que deixar o governo".
} 


\section{2 "Querida marquesa": as cartas e o gosto pela política adquirido por Domitila}

O início do romance entre Domitila de Castro Canto e Melo e o imperador Pedro I ocorreu quando este, após a partida, em 14 de agosto de 1822 do Rio de Janeiro, em direção à sitiada São Paulo, dias depois, já estando no subúrbio paulista, conheceu a futura marquesa de Santos. Uma jovem, pouco mais velha que ele, com dois filhos, separada de um marido violento que tentara assassiná-la anos antes. Embora não esteja registrado em documentos oficiais, consta de uma das cartas do imperador para a amante a data do profícuo encontro, quando o próprio monarca afirma que a intimidade entre eles começou em 29 de agosto de 1822 (RANGEL, 1984, p. 101).

Proclamada a Independência do Brasil em São Paulo, d. Pedro retornou para o Rio de Janeiro, mas deixava plantado o princípio de uma história que, em breve, se estenderia à Corte carioca. Em 17 de novembro ele escrevia para Domitila encantado com as cartas que esta lhe enviara, além de dar a entender que falara com o pai dela, João de Castro, que o havia acompanhado no retorno à Corte, que a filha se encontrava grávida dele: "Tive arte de fazer saber a seu pai que estava pejada de mim (mas não lhe fale nisto) e assim persuadi-lo que a fosse buscar e a sua família, que não há de cá morrer de fome, muito especialmente o meu amor, por quem estou pronto a fazer sacrifícios" (RANGEL, 1984, p. 53).

A partir do persuasivo convite, toda a família, com exceção dos irmãos mais velhos, João e José de Castro, militares aquartelados no sul do Brasil, mudou-se para o Rio de Janeiro. Junto com Domitila foram os filhos do primeiro casamento, os pais, a avó, irmãos, cunhados, tios e primas viver na capital do nascente Império brasileiro, onde contaram, de fato, com a proteção de d. Pedro, que os manteve em condições muito além do que uma família qualquer na Corte.

A data exata em que Domitila se instalou na Corte não é certa, mas a correspondência entre os amantes e algumas resoluções e despachos oficiais mostram que a chegada deve ter ocorrido entre janeiro e março de 1823. A irmã, Ana Cândida, chamada de nhá Cândida por d. Pedro, e o marido, o militar Carlos Maria Oliva, mudaram-se para o Engenho Velho; o cunhado, Boaventura Delfim Pereira, e a esposa, Maria Benedita, irmã mais velha de Domitila, compraram uma chácara na ladeira da Glória, próxima da igreja de Nossa Senhora da Glória do Outeiro. Domitila, os pais e os filhos do primeiro casamento estabeleceram-se em uma casa em Mata-Porcos, onde hoje se localiza o bairro do Estácio. Porém, a favorita não se limitaria a uma pequena casa ou a apartamentos espaçosos no Paço, mas teria um palacete comprado por d. Pedro, em São Cristóvão, distante do palácio imperial apenas o suficiente para que o seu cotidiano pudesse ser alcançado por uma luneta utilizada pelo monarca para vigiar os passos da amante:

Diversas vezes ficou numa janela do palácio espionando com uma luneta o palacete dela. Mandava recados por escravos de confiança, inquirindo de quem eram as carruagens que estavam estacionadas em frente à casa ou informando-a de que não adiantava fechar as janelas porque ele sabia que ela estava lá. E, quando ela as deixava abertas, ele escrevia: "[...] a propósito daquela janela do teu quarto, quero dizer-te que fica aberta mais do que deve e eu não gosto disso" (REZZUTTI, 2012a, p. 112).

A partir de sua instalação no palacete de São Cristóvão, Domitila e o imperador vão viver um conhecido caso de amor, registrado em inúmeras cartas trocadas entre eles, das quais, infelizmente, restam somente aquelas que foram recebidas por Domitila, provavelmente, por ser o imperador mais cuidadoso em destruir as que recebia da amante.

6 Revista Estudos Feministas, Florianópolis, 26(2): e48809 
As cartas que d. Pedro escrevia refletem a própria trajetória do romance, inicialmente, chamando a favorita de Titília, meu bem, meu amor, meu encanto, amor do meu coração, filha, e reservando às últimas epístolas, quando dos estertores da relação, o tratamento de "Querida Marquesa", como na missiva de 21 de dezembro de 1828, uma das poucas com datação. No entanto, ao longo dos sete anos em que mantiveram o relacionamento, as cartas endereçadas à Domitila não foram poucas e entre as já localizadas podem ser contadas mais de duzentas, espalhadas por diversas coleções em diferentes instituições e países.

Com conteúdo essencialmente íntimo, as cartas mostram o profundo envolvimento de d. Pedro com a marquesa, a quem procurava agradar de muitas maneiras, sugerindo que o romance público pode ter contribuído com o descontentamento entre o imperador e seus súditos, particularmente, aqueles mais próximos, pois a personalidade da favorita não era dada a indiferenças e assim como ela possuía inúmeros aliados, igualmente na Corte fervilhavam os inimigos "dos amores", como o próprio d. Pedro se referia ao seu caso com Domitila.

Soma-se a isso uma inegável prova da crescente influência política de Domitila sobre o imperador, quando, em maio de 1826, este decide reconhecer a filha que tivera com a amante em 1824. O barão de Mareschal, em ofício a Viena, informaria que: "Há muito tempo que a senhora viscondessa de Santos trabalhou neste caso, Sua Majestade recusava, mas, provavelmente, a morte do filho que ele teve com essa dama e a popularidade que lhe deu a renúncia a Portugal, tê-lo-ia feito arriscar agora esse ato".9

O empenho da marquesa pelo poder não parou no reconhecimento da filha e seguiu-se a este ato a concessão do título de duquesa de Goiás à menina, utilizando-se da "grandeza" de duque, que no sistema nobiliárquico brasileiro era um título reservado apenas a pessoas pertencentes à família do soberano. Com essa atitude do imperador, a marquesa não só demarcava sua condição para além de uma simples amante real, mas assegurava que jamais voltaria a ser uma mulher comum, muito menos seriam os frutos da sua relação com o soberano. Ao protagonizar esse e outros enredos no cenário do primeiro reinado brasileiro, Domitila desenvolveu o gosto e o destemor pela política - que a acompanhariam durante seus próximos anos de vida.

À certa altura, as relações de poder da marquesa tornaram-se tão intensas que ela e os demais súditos chegaram a acreditar na possibilidade de, mais uma vez, repetir-se as circunstâncias que permitiram o casamento de madame de Maintenon e Luiz XIV. Na Crônica Geral do Brasil, Tomo II (Alexandre José de MELO MORAIS, 1886, p. 283), ${ }^{10}$ consta a informação de que d. Pedro, diante da dificuldade em encontrar uma nova noiva na Europa, após a morte de Leopoldina, teria a intenção de se casar com Domitila. A fonte da informação, como revela o autor (ldem) em uma nota de pé de página, seria a condessa de Iguaçu, última filha do casal, que teria confessado a ele essa reminiscência da mãe. Nas cartas, em que pese a exposição de um soberano apaixonado, em pleno desfrute da intimidade de sua amada, nada sugere esse desfecho.

Contudo, as cartas revelam um imperador disposto a atender aos caprichos da amante, ou, pelo menos, essa era uma demonstração constante aos súditos, fazendo com que a favorita fosse temida quando contrariada, pois tal atitude poderia ter graves consequências, segundo seus biógrafos, desde o fechamento de um teatro em que havia sido impedida de entrar, até o desprezo público do imperador aos mais antigos integrantes

${ }^{9}$ Relatório $n^{\circ} 13$, RIHGB, 13 de junho de 1826. Tradução livre dos autores.

${ }^{10}$ Alexandre José de Melo Morais foi um médico que nasceu em Maceió, em 23 de julho de 1816, e morreu no Rio de Janeiro em 05 de setembro de 1882. Escreveu vários livros sobre a história do Brasil baseados em documentos e narrativas que ouviu ao longo da vida. 
da Corte imperial. Nas biografias baseadas em documentos e cartas, Domitila é tratada como uma mulher perspicaz e que soube desfrutar amplamente de sua condição privilegiada, não só em termos econômicos e sociais, mas se envolvendo em disputas políticas, sendo, por vezes, até mesmo procurada por embaixadores estrangeiros para interferir junto ao soberano. Tal influência/atuação sobre d. Pedro, revestida de escopo biográfico para demonstrar a personalidade da amante, encontrou nas missivas trocadas entre o casal, bem como naquelas que tratavam do relacionamento dos dois, material suficiente para consolidar a imagem de uma mulher que usou de todas as possibilidades femininas para atingir seus objetivos junto ao imperador.

Tratando da legitimidade do conteúdo dos documentos, Cécile DAUPHIN e Danièle POUBLAN (2002) assinalam que o gênero biográfico "é particularmente ávido por registros epistolares, pela capacidade que eles têm de produzir 'excesso de sentido' que insufla força, convicção e veracidade aos comentários" (p. 75). Tal percepção fica bastante evidente nas biografias baseadas em cartas de $d$. Pedro endereçadas à marquesa, quando trazem à tona mais do que um romance, mas todo um cotidiano em que a convivência entre os amantes proporcionou a Domitila participar das questões políticas que assolavam o país e preocupavam o imperador, fazendo com que ela aprendesse ou aprimorasse com ele o gosto pela política, compartilhando, embora por vezes dissimulada, a condução do governo durante boa parte do primeiro reinado.

Desde o início da relação entre Domitila e d. Pedro a favorita já demonstrava sua propensão para interferir nas decisões do monarca. Ainda quando estava em São Paulo, antes de se mudar para a Corte, aparece a influência/atuação de Domitila sobre as atitudes do, então, príncipe regente e futuro imperador. Sua primeira aproximação com o soberano já carregava algumas reivindicações, sendo a principal delas o divórcio do marido e a guarda dos filhos, mas, provavelmente, caso o imperador se interessasse, outras pendências da família precisavam ser tratadas.

Apesar de ter solicitado a sua reforma no exército, em abril de 1822, na patente de tenente coronel, João de Castro estava, assim como a grande maioria dos militares portugueses no Brasil, sem receber o soldo já fazia meses. Vivia do aluguel de mulas para descida e subida de mercadorias pela serra do Mar, próximo a um local denominado Moinhos (REZZUTTI, 2012a, p. 55).

O problema da aposentadoria do pai, descrito acima, a pendência de seu divórcio com o marido que a havia esfaqueado, além do pleito de guarda dos filhos e a deportação do cunhado para Jundiaí, por ter participado da bernarda" contra os Andradas, já foram assuntos encaminhados logo nos primeiros encontros, nos quais se iniciaram as "intimidades". Tal fato demonstra que a vida de Domitila junto a d. Pedro I não se resumiria aos quartos, mas iria para muito além deles.

Para atender às aspirações de Domitila e aos seus próprios desejos de publicizar o relacionamento com a amada, $d$. Pedro foi capaz de atitudes bastante singulares. Entre inúmeras tentativas de impor a favorita na sociedade da Corte, o imperador registra em carta $^{12}$ para Domitila que teria mandado fechar a tribuna da Capela imperial reservada às damas do paço, enviando-Ihe a chave, para que somente ela pudesse abrir, ficando todos sem lugar até que chegasse. Tratava-se de uma escancarada revanche pelo destrato feito à favorita em sua aparição na cerimônia religiosa anterior.

\footnotetext{
"O movimento conhecido como "bernarda" foi uma revolta ocorrida em São Paulo, liderada por Francisco Inácio de Sousa Queirós, homem com grande força políitica na região de Sorocaba, ao qual se juntaram opositores dos Andradas.

${ }^{12}$ Carta não datada, constante do arquivo sob a guarda da Hispanic Society of America.
} 
Embora capaz de perseguir os maridos das mulheres que a insultavam, como afirma nessa mesma carta: "além disso, hei de tratar os maridos de bonito modo, e eu lhe prometo que mais nada hão de fazer aos amores" (REZZUTTI, 2011, p. 133), nem sempre o amante conseguia atender a todos os pedidos da favorita. No entanto, o grau de consternação que demonstra por não poder fazê-lo indica a extensão dos poderes da marquesa:

As razões em contrário à ida do Tomás são as mesmas por mim dadas ontem a mecê, e acresce mais que, indo o seu batalhão e sendo ele trocado, o seu contrário em São Paulo dirá que isto foi feito de propósito para que o Tomás lhe não pague, vista esta razão que acresce em contrário deve ir, pois vai o seu corpo, e ele que faça um requerimento requerendo meios de conciliação com o seu adversário, o que é muito fácil. Sinto infinito quando não posso fazer o que mecê pede; mas é o que acontece a quem como eu deseja manter a justiça e a disciplina militar, que muitas vezes tem de dar golpes em sua alma e faltar a quem ama quando the pede qualquer coisa. Pode dispor de tudo o que for propriedade. Deste seu desvelado, constante, verdadeiro, fiel, agradecido, e todo amante. O Demonão (REZZUTTI, 201 1, p. 145 [grifo nosso]).

Rezzutti (2012a) afirma que "com a sociedade querendo ou não, d. Pedro havia transformado sua amante em um elemento político" (p. 103). O ápice dessa condição pode ser verificado nos acontecimentos de julho de 1825, quando a marquesa intermediou as negociações de sir Charles Stuart, diplomata britânico e plenipotenciário de d. João Vl, encarregado de acertar os detalhes do tratado para o reconhecimento da independência do Brasil. "Stuart visitou Domitila primeiro, antes de se avistar com a imperatriz" (Idem), e, segundo o inglês, Domitila teria sido a responsável por convencer o imperador a aceitar determinados termos do tratado. ${ }^{13}$

Em um trecho das memórias de Antônio de Menezes Vasconcelos de DRUMMOND (1886 [1836]), ${ }^{14}$ publicadas em 1836 como "Annotacoes De A. M. V. De Drummond a sua biographia", o autor, um dos partícipes do processo de Independência, além de partidário dos Andradas e, consequentemente, admirador da imperatriz Leopoldina e opositor veemente de Domitila, acusa a favorita de ter tal alcance de influência/atuação, a ponto de ter sido a responsável pela queda dos Andradas e pelo fechamento da Assembleia Constituinte:

Ambos estes partidos rodearam a Domitilla [partido português e partido republicano], e esta mulher em semelhante conjunctura foi o centro das cabalas e intrigas que deram em resultado a dissolução da Constituinte, e a prisão e deportação de alguns dos seus mais temíveis adversários (DRUMMOND, 1836, p. 98).

De acordo com o memorialista, não só Domitila teria sido quem mais "serviu nesta empresa" de dissolver a Constituinte, como "teria recebido doze contos de réis" em prêmio pelo seu trabalho. Em que pese se tratar de um desafeto da favorita, segundo o qual "esta [é] mulher, que tantos males causou ao Brasil", o autor afirma ter visto e lido tais informações em uma carta escrita pela imperatriz Leopoldina a José Bonifácio de Andrada, por volta de

${ }^{13}$ Em carta para George Canning, Secretário dos Assuntos Estrangeiros britânicos, Stuart afirmou que, graças à intervenção de Felisberto Caldeira Brant, futuro marquês de Barbacena, e de Domitila, d. Pedro aceitou determinada modificação na fórmula de como ele havia sido feito imperador do Brasil que aparecia no tratado da Independência (REZZUTTI, 2012a, p. 103).

${ }^{14}$ Antônio de Menezes Vasconcelos de Drummond é um dos primeiros brasileiros a participar do governo português estabelecido no país, desde 1808, com a chegada da Família Real, ocupando cargos até ser exilado junto com os irmãos Andradas em 1824. Viveu, portanto, os acontecimentos do Brasil Colônia até a consolidação da Independência de Portugal. As Annotacoes De A. M. V. De Drummond a sua biographia tratam-se de acréscimos feitos pelo próprio ao seu verbete no Biographie Universelle et Portative des Contemporains. 
novembro ou dezembro de 1824 (DRUMMOND, 1836, p. 99). Mas Drummond não era e nem seria o único a acusar Domitila de tirar vantagens financeiras de sua posição com o imperador.

O que vale notar neste relato é que nem seus inimigos tinham dúvida de seu poder político nas decisões de estado, ao contrário, julgavam que ela era a protagonista, atribuindo-Ihe uma posição determinante, que não parece possível a uma única mulher, naquele contexto, diante de acontecimentos tão complexos.

Com a viuvez de d. Pedro e a iminência da chegada da nova imperatriz Amélia, Domitila é exilada definitivamente em São Paulo em agosto de 1829, e o imperador, momentaneamente, deixa vago o cargo de favorita, enquanto desfruta a jovialidade $e$ beleza de sua nova esposa. Longe da Corte, Domitila, acostumada a ser o centro das atenções e tensões políticas, não demora a encontrar meios para tornar sua influência prioritária também nessa região. Para esse fim, agora não vai se conformar com o lugar de favorita, mas usará de seus predicados para tornar-se a mulher oficial do presidente da Província, Rafael Tobias de Aguiar. Se não podia mais controlar os destinos no Império, continuaria a fazê-lo nos limites da sua Província de origem.

\section{Da marquesa cortesã à militante liberal: ressonâncias da relação com o poder}

Entre os feitos de Domitila, um deles parece ser o que reflete um dos aspectos mais significativos de sua personalidade, o gosto pelo poder e pelos locais onde ele se concentrava. Alberto Rangel (1928), nos apensos de seu livro Dom Pedro Primeiro e a Marquesa de Santos, conta que a maçonaria prosperava na capital da Província de São Paulo, com a mais antiga loja datando de 13 de março de 1832. Ainda segundo os escritos do mesmo autor (RANGEL, 1928, p. 298), Domitila teria sido apresentada à maçonaria pelo próprio imperador, e permaneceu com essa prática, frequentando uma loja maçônica de adoção de senhoras, na qual "colhiam-se os adeptos não na borra das massas, mas no créme da sociedade, que servindo à confraria político-social, gozava da intimidade de mistérios de templo hindu e da glória de tradições honrosas" (RANGEL, 1928, p. 298). "Pois bem", assegura Rangel (1928, p. 298), baseado nos testemunhos publicados "pelo doutor Pires de Almeida em uma revista carioca", que a marquesa de Santos, "pelo régio amante ali iniciada [na maçonaria], presidia na qualidade de Venerável às mais calorosas sessões. Substituída na efetividade pelo padre Manoel Joaquim do Amaral Gurgel, mais tarde diretor da Faculdade de Direito", era assessorada pelos Vigilantes Clemente Falcão Filho e João Theodoro Xavier, adjuntos da Faculdade. Vale destacar que o próprio autor observa que "nessas congregações femininas, acima do grau três a hierarquia é intransponível" (RANGEL, 1928, p. 298), mas, ao que parece, era difícil que algo não fosse totalmente intransponível para Domitila.

A maçonaria nesse período, primeiras décadas do século XIX, tinha um papel atuante nos movimentos políticos e contava com a participação de parte dos integrantes do governo imperial em suas lojas, aproximando e constituindo redes de sociabilidade e de influência. Por outro lado, era concebida como uma sociedade cercada de mistérios, envolta a superstições e rituais imaginários que desagradavam, principalmente, ao clero. Para a marquesa, um lugar ideal de atuação, do qual não prescindiria, ainda mais tendo sido "iniciada" pelo próprio imperador, como afirma Rangel. Não é difícil imaginá-la como "venerável", presidindo sessões entre homens destacados das Províncias e do Império, discutindo questões eivadas de contradições políticas e posicionando-se em relação a elas. Provavelmente, a sua atuação na maçonaria, sendo mulher e com um passado 
bastante incomum, também tenha contribuído para a imagem cristalizada de sua personalidade.

No que se refere à disposição dos homens do Império para as questões políticas, o fazer e desfazer das oportunidades partidárias, as associações e rupturas comuns na vida pública, com a marquesa, não eram diferentes. Rangel (1928) descreve:

A Marquesa viera do regime colonial e testemunhara todos os ensaios da Independência e do Constitucionalismo. A variedade dos atos, no espetáculo nacional fremente acabou por empolgá-la. Vemo-la então se envolver francamente, em seguida, à Maioridade, nos pleitos eleitorais de S. Paulo, enfileirando-se na falange dos liberais e regionalistas. Aconteceu que os azares do partidarismo a puseram ao lado das Andradas em 1842; estes e D. Domitila formados em cerra fila à roupeta de Diogo Feijó! Impagável e instrutiva a contradança da "michella" de 1823 com os jacobinos da Constituinte, dos "caramurus" da Regência com o ministro da Justiça de 1831! (p. 299).

É provável que a convivência com o imperador e sua centralidade no cenário político da Corte tenham sido características incorporadas à personalidade da ex-favorita real, fazendo com que ela, após tantas desilusões vividas e experimentadas, decorrentes das manifestações conservadoras contrárias ao soberano, se tornasse uma militante liberal atuante. Numa época em que as brasileiras não tinham direito a votar e, muito menos, a se candidatar a cargos políticos, a marquesa participava ativamente da vida política paulista, como bem explicita Rangel (1928) ao destacar que "em tal período de efervescência eleitoral, revelou a Marquesa a energia e o destemor das modernas sufragistas inglesas. [...] Comparecia às urnas opondo-se com firmeza às trampolinas dos contrários" (p. 299). Para Rangel, "os seus recursos de cabala eram inesgotáveis" (ldem); quando os conservadores, em certa ocasião, vencendo um pleito, desejavam comemorar a vitória com uma banda de música, a marquesa não teve dúvida, alugou e escondeu a banda na sua residência, a fim de murchar o entusiasmo dos seus adversários.

Com efeito, não era sem razão que a marquesa despertava em seus desafetos a mais odiosa impressão, afinal, rompendo com a condição social imposta às mulheres, ela imiscuiu-se na política, campo então exclusivamente masculino, e os rancores produzidos por sua conduta e atuação acabaram por reverberar em sua biografia. Rangel (1928) transcreve nos apensos de seu livro um manuscrito, localizado e datado de Pindamonhangaba, de 18 de fevereiro de 1861, "conservado em poder do Sr. barão Homem de Mello", que assim se refere a ela:

Um episódio da história pátria 1822 a 1830 . A Marquesa de Santos. ... De feito a fascinação dos imperantes por mulheres do povo tem muitas vezes produzido na história das nações resultados de alta importância política, tendo elas quase sempre em suas mãos o sceptro do domínio supremo. No Brasil deu-se esse fato no primeiro reinado. O Imperador Pedro I apaixonou-se em S. Paulo no ano de 1822 por uma mulher perdida, que, exercendo sobre seu ânimo um ascendente notável, veio a ter uma grande influência nos negócios políticos do país. Muitos acontecimentos importantes da época explicamse por sua intervenção (p. 451).

Complementava o depoente transcrito por Rangel que não havia ninguém melhor do que ele para escrever a "história d'essa mulher. Possuo a seu respeito documentos importantes; fui seu inquilino em S. Paulo; ai conheci-a de perto, e no ano de 1858 tive ocasião de com ela tratar" (RANGEL, 1928, p. 451).

A alcunha de "mulher perdida", além de outras inúmeras designações depreciativas que foram atribuídas a Domitila, decorrem não apenas de sua condição de amante, mas, principalmente, porque a marquesa circulava pelos espaços públicos, tinha funções que 
superavam em muito a vida doméstica, revestindo-se de "uma mundanidade tão frenética quanto ritualizada" (PERROT, 1998, p. 22), à qual poucas mulheres tinham permissão para desfrutar, notadamente, mulheres estrangeiras que "exiladas", às vezes, "se interessavam pela coisa pública" (Idem, p. 62). A marquesa era brasileira, não provinha da nobreza ou burguesia enriquecida, no entanto, mesmo depois de ser deixada pelo imperador, continuou recebendo em seus salóes, participando da vida política da Província de São Paulo e das disputas que assolavam o Império. Muito longe de se tornar apenas a "secretária da família", como sinaliza Perrot acerca das mulheres educadas no oitocentos (Ibidem, p. 74), a marquesa usou seus ensinamentos obtidos junto ao imperador para servir a ela própria, tendo posições políticas demarcadas e opinando nas questões que chegavam até ela.

Com essa atitude, rompia com todas as convenções e comportamentos esperados de sua condição feminina naquele tempo e lugar, o que, certamente, contribuiu para a imagem negativa que sobreviveu a ela. Como parte dos defeitos imputados à marquesa estava ainda a mesquinhez, quando suas recepções são comparadas por Rangel (1928) aos "jantares de magro da Maintenon" (p. 300), baseando-se nas crônicas do jornal paulista e caricato denominado Cabrião. "Imputou-se à Marquesa ser forreta, mercando legumes e ratinhando-os, vendendo toucinho à sua escravatura" (ldem).

Entre partidários e desafetos, a marquesa ia tocando sua longeva vida na capital da Província paulista, sem jamais se esquivar da política, supostamente com habilidades apreendidas com o imperador, ou, talvez, fosse essa a impressão que pretendia passar. Uma de suas cartas para o genro, o conde de Iguaçu, que ela chama de "primo", falando sobre a política durante o reinado de d. Pedro Il, demonstra o intenso efeito das circunstâncias vividas até se tornar uma militante liberal paulista.

... Primo não poso deixar agora de the falar em politica, pois o governo o que me parece he todo fazer mal ao Imperador mandarnos hum agente do Papa dahi para ca como Presidente Papa xamão o hózebio e como o Povo não queirão votar no genro deste malvado esse traste do genro do lobo - e não queirão dar os seos votos Aqueles $\mathrm{a} \mathrm{q}^{\mathrm{m}}$ o Prezidente ordenna seja este povo emcomodado gasta se todos os dinheiros dos cofres $\mathrm{p}^{a}$ se fazer desordens - não sendo nada Nada a favor do Imperador o que nos vale he so estarem pesoas $\mathrm{m}^{\text {to }}$ baixas ouvida deste desgrasado Presidente. Já houverão duas Mortes em casa Pava e não tem havido em Mogi porque o pobre do curão fes $q^{e}$ fosse José bonifacio e João e o padre Mamede que $\mathrm{m}^{\text {to }}$ fizerão $\mathrm{p}^{a}$ não corer sangue $o$ Presidente mandou o bobo do Pinto e Mandou o diabo do genro (a) hum diabo revolucionario que já quis matar o lente em Pernambuco este homem de maranhão veio reseber orden do Presidente $\mathrm{p}^{a}$ se por a testa de soldados para fazer o que bem the parecer. Eu Primo $\mathrm{m}^{\text {to }}$ e $\mathrm{m}^{\text {to }}$ estimo ao Imperador e tenho tantos motivos $\mathrm{p}^{a}$ hisso e assim sinto $\mathrm{m}^{\text {to }}$ helle não ver as tramas que os malvados se estão armando não aqui porque graças $a D^{\circ}$ os que (a) so dezejao pais no brasir e o Imperador a testa (a) de le encomodar. Mas quando haja alguma coiza sobre o Imperador Ihe heide mandar contar. Manuscripto conservado na Bibliotheca Nacional do Rio de Janeiro (RANGEL, 1928, p. 451). ${ }^{15}$

Embora com uma escrita intensa, mesmo para os padrões do português arcaico, supõe-se que redigir não era o principal talento de Domitila e a menos que se conhecessem suas preferências políticas, haveria alguma dificuldade de entendê-las no descrito em suas cartas. Some-se a isso o fato de que, tendo como base os seus escritos, não se pode saber exatamente o que ela pensava, pois, contrariamente ao que escrevia, suas opiniões poderiam ser completamente inversas e enviadas nas cartas apenas para serem lidas ou divulgadas por alguém. ${ }^{15}$ A ortografia foi conservada como consta no original pela dificuldade de transcrever sem alterar o conteúdo
e a intenção da missivista.

12 Revista Estudos Feministas, Florianópolis, 26(2): e48809 
Todavia, certo é que atuava como militante da causa liberal, com todas as contradições que essa posição política oferecia na São Paulo de meados do século XIX. Ainda assim, essa disposição partidária pode ser constatada em seus escritos, sejam eles sinceros ou meros propagadores de contrainformações.

Aos leitores de mais de 150 anos depois dos fatos ocorridos, não deixa de surpreender a veemência de suas atitudes - desde a exposição pública do caso com o imperador, à aliança com Tobias de Aguiar no "exílio" da Corte - e o eterno envolvimento nas questões políticas, aspecto singular de gênero para a época e o contexto.

\section{Finalizando...}

Stefan Bollmann (2006; 2007), em suas publicações Las mujeres que leen son peligrosas e Las mujeres que escriben también son peligrosas, afirma que as mulheres de outros tempos escreviam em condições muito diferentes das dos homens. Além do que, só o fato de escrever já era perigoso. Trazendo essas afirmações para o tempo e o contexto de Domitila, sua escrita teve que forçosamente se equiparar a de um homem, o imperador, para que pudesse ser entendida por ele e consolidar uma troca de correspondência, não só confidencial, mas suficientemente clara para que os seus objetivos fossem alcançados. Provavelmente, para uma moça que não havia recebido uma educação refinada com preceptores ou professores contratados para tal ${ }^{16}$ (VASCONCELOS, 2005), colocar-se à altura de ser entendida e admirada pelo imperador deve ter exigido dela muito esforço, em que pese Meri Torras FRANCÈS (2001) assegurar "a pretendida facilidade feminina para a escrita epistolar". ${ }^{17}$

Embora não se tenham vestígios de que Domitila lia autores em voga na época, primeiras décadas do século XIX, ou discutia sobre algum outro assunto que não fosse política, mesmo esse tema de sua preferência está constantemente afinado ao seu cotidiano e a seus desejos e impressões imediatas.

Contudo, isso não a impediu de exercer enorme influência/atuação nos assuntos de estado e nem de estar relacionada, invariavelmente, às grandes questões políticas que envolveram o país, fosse ou não verdadeira a sua participação. A julgar pelo lugar de favorita que ocupou junto ao imperador, em um tempo em que tais excessos já não eram tão comuns, Domitila foi mais influente do que uma simples amante e, mais tarde, do que uma mulher casada com o presidente da Província de São Paulo, desempenhando apenas o seu papel social.

Por outro lado, é possível que sua participação tenha sido muito maior do que os registros fragmentados que chegam aos nossos dias, considerando ainda que, colecionando desafetos, esses contribuíram para que muito da sua história fosse apagada ou infamada. Certo é que, num contexto de mulheres silenciadas (PERROT, 2005), ela soube fazer sobressair sua fala, ainda que pela locução dos homens. Demoraria mais de um século para que "os debates relativos a uma representação partidária das mulheres" (PERROT, 1998, p. 117) viessem a sacudir o final do novecentos. Nesse sentido, Domitila é pioneira; embora imperiosamente forçada a ter uma posição políica, sua atuação é de vanguarda, considerando desde sua atitude de participação em uma loja maçônica até a militância no Partido Liberal.

\footnotetext{
${ }^{16}$ De acordo com o estudo de Vasconcelos (2005), as elites oitocentistas educavam seus filhos e, especialmente, as filhas mulheres, majoritariamente na modalidade de educação doméstica, com a contratação de preceptores e professores particulares que atuavam nas casas dos aprendizes, sob a escolha e fiscalização exclusivas da família. Como essa opção por educar na casa tinha um alto custo para as famílias, sua utilização era afeita às camadas mais favorecidas econômica e socialmente da população, o que não era o caso da família de Domitila.

${ }^{17}$ Texto original em Espanhol. Tradução livre dos autores.
} 
Perrot (1998) afirma que "o acesso das mulheres ao poder político sempre e em toda parte foi difícil" (p. 1 18). Restava a elas ocultarem-se à sombra de homens poderosos e isso foi o que fizeram as escolhidas como favoritas, cuja personalidade afinava-se também com esses propósitos. Como corrobora Antje WINDGASSEN (2008), "as mulheres dos ditadores não desempenharam apenas a função de amantes ou esposas, mas a maior parte foi muito além disso". Esse é o caso de Domitila de Castro Canto e Melo, demonstrando que as rígidas convenções de gênero, às vezes, eram escamoteadas, embora fossem as prerrogativas femininas que determinassem aquelas que teriam voz. Segundo Perrot (2008), atravessar a fronteira da política foi a mais difícil tarefa das mulheres e, se por um lado, as favoritas abriram esse caminho, por outro o tornaram mais eivado de preconceitos, discriminações e sob suspeita.

\section{Referências}

ABBOTT, Elizabeth. Amantes. Uma história da outra. Rio de Janeiro: Record, 2016.

BOLLMANN, Stefan. Las mujeres que leen son peligrosas. Madrid: Maeva, 2006. Las mujeres que escriben también son peligrosas. Madrid: Maeva, 2007.

CASA de Valois. Disponível em: https://pt.scribd.com/document/249174297/Casa-de-Valois. Acesso em: 23/01/2017.

CORRESPONDÊNCIA do barão de Mareschal. Revista do Instituto Histórico e Geográfico Brasileiro. Brasília, Rio de Janeiro, n. 339, IHGB, 1983.

CUNHA, Maria Teresa Santos. "Diários pessoais. Territórios abertos para a história". In: PINSKY, Carla Bassanezi; LUCA, Tania Regina de (Orgs.). O historiador e suas fontes. São Paulo: Contexto, 2011. p. 251-280.

DAUPHIN, Cécile; POUBLAN, Danièle. "Maneiras de escrever, maneiras de viver. Cartas familiares no século XIX". In: BASTOS, Maria Helena Camara; CUNHA, Maria Teresa Santos; MIGNOT, Ana Chrystina Venâncio. Destinos das letras. História, educação e escrita epistolar. Passo Fundo: UPF, 2002. p. 75-88.

DIGNEFFE, Françoise. "Do individual ao social: a abordagem biográfica". In: ALBARELLO, Luc et al. (Orgs.). Práticas e métodos de investigação em ciências sociais. Lisboa: Gradiva, 1997. p. 203-245.

DRUMMOND, Antônio de Menezes Vasconcelos de. Anotações de A. M. V. de Drummond à sua Biografia. 1.ed., 1836. In: BIBLIOTECA NACIONAL do RIO de JANEIRO. v. XIII. Rio de Janeiro: Leuzinger e Filhos, 1886. Anais..., (3a Parte)

FERRAROTTI, Franco. Histoire et histories de vie. La méthode biographique dans les sciences sociales. Paris: Méridiens, 1983.

FRANCÈS, Meri Torras. Tomando cartas en el asunto: las amistades peligrosas de las mujeres con el género epistolar. Zaragoza: Prensas Universitarias de Zaragoza, 2001.

FREIXO, Andre de LemOs; COELHO, Patrícia. "O ensino renovado de história pelo catedrático do Colégio de Pedro II, Jonathas Serrano". Rev. bras. hist. educ., Maringá, v. 15, n. 3[39], p. 261-292, setembro/dezembro 2015. Disponível em: http://www.rbhe.sbhe.org.br/ index.php/rbhe/article/view/839. Acesso em: 16/09/2016.

FUCHS, Eduard. Historia ilustrada de la moral sexual. 3. La época burguesa. Madrid: Alianza Editorial, 1996.

MELO MORAIS, Alexandre José de. Crônica Geral do Brasil. Rio de Janeiro: Garnier, 1886. 2v.

PEREIRA, Ana Cristina; TRONI, Joana. Amantes dos reis de França. Lisboa: Esfera dos livros, 2009.

PERROT, Michelle. Mulheres públicas. São Paulo: EDUNESP, 1998.

. As mulheres ou os silêncios da história. Bauru: EDUSC, 2005.

. Mi historia de las mujeres. Buenos Aires: Fondo de Cultura Económica, 2008.

14 Revista Estudos Feministas, Florianópolis, 26(2): e48809 
História dos quartos. São Paulo: Paz e Terra, 2011.

RANGEL, Alberto. Dom Pedro Primeiro e a marquesa de Santos. 2.ed. Tours: Arrault e Companhia, 1928.

Cartas de Pedro I à marquesa de Santos. Rio de Janeiro: Nova Fronteira, 1984.

RELATÓRIO n 13. Revista do Instituto Histórico e Geográfico do Rio de Janeiro, n. 339, p. 185, 13 de junho de 1826.

REZZUTTI, Paulo. Titília e o Demonão. Cartas inéditas de d. Pedro I à marquesa de Santos. São Paulo: Geração Editorial, 2011. $2012 a$

Domitila, a verdadeira história da Marquesa de Santos. São Paulo: Geração Editorial,

"Marquesa de Santos, mulher de fibra". Revista de História da Biblioteca Nacional, Rio de Janeiro, v. 82, p. 48-51, 2012b.

THOMSON, Oliver. História do pecado. Lisboa: Guerra e Paz, 2010.

VASCONCELOS, Maria Celi Chaves. A casa e seus mestres: a educação no Brasil de oitocentos. Rio de Janeiro: Gryphus, 2005.

. "A escrita cotidiana no diário de lembranças da viscondessa de Arcozelo: fragmentos (auto)biográficos de um egodocumento". In: VASCONCELOS, Maria Celi Chaves; CORDEIRO, Verbena Maria Rocha; VICENTINI, Paula Perin (Orgs.). (Auto)biografia, literatura e história. Curitiba: CRV, 2014. p. 95-114.

WINDGASSEN, Antje. Casadas com o poder. Lisboa: Quetzal Editores, 2008.

[Recebido em 01/02/2017 e aprovado em 11/05/2017]

\begin{abstract}
The Marchioness of Santos and the Taste for the Power: from "Favorite" to Liberal Militant

Abstract: The article focuses on aspects of the biography of Domitila de Castro Canto e Melo, especially her relationship with power, developed from the condition of lover of the emperor Pedro I, registered in the lefters exchanged between the writers from 1822 to 1829, until her long life after leaving the Court. The methodological procedures refer to a bibliographical research, particularly in dialogue with authors who have studied the recomposition of the marchioness's life and others who analyzed the situation of women and their possibilities in the nineteenth century. It is concluded that the marquise de Santos, unlike most women of her time and context, had a predilection for politics, influencing the emperor while occupying the place of "favorite", as well as remaining involved in political and party affairs already in her definitive residence in the Province of São Paulo. Keywords: Marquise de Santos; Emperor Pedro I; Female condition; Power relations
\end{abstract}

Maria Celi Chaves Vasconcelos (maria2.celi@gmail.com) é professora do Programa de Pós-Graduação em Educação da Universidade do Estado do Rio de Janeiro (Proped/UERJ). Chefe do Departamento de Políticas, Avaliação e Gestão da Educação Faculdade de Educação (DEPAG/UERJ), é pós-doutora em Educação pela Universidade do Minho. Doutora em Educação pela PUC-Rio, coordena o Grupo de Pesquisa "História e memória das políicas educacionais no território fluminense". Bolsista de Produtividade do CNPq.

Paulo Marcelo Rezzutti (prezzutti@gmail.com) é membro titular do Instituto Histórico e Geográfico de São Paulo. Pesquisador, escritor e biógrafo. Integra o Grupo de Pesquisa "História e memória das políticas educacionais no território fluminense" - CNPq/UERJ. Autor dos livros: Titília e o Demonão. Cartas inéditas de d. Pedro I à marquesa de Santos; Domitila, a verdadeira história da Marquesa de Santos; D. Pedro. A história não contada; entre outros. 